\title{
A UTILIZAÇÃO DE ERVAS E PLANTAS MEDICINAIS COMO FORMA DE CUIDADO À SAÚDE MENTAL EM TEMPOS DA COVID-19
}

Jamine Bernieri

DOI: http://dx.doi.org/10.18616/intcov37

Neste momento de enfrentamento da pandemia do coronavírus é comum ouvir pessoas queixando-se de sintomas relacionados ao sofrimento mental. Sabe-se que os problemas de saúde mental já acometiam um elevado número de pessoas em nossa sociedade, porém com a presença desse "inimigo invisível e ameaçador", o coronavírus, circulando entre os indivíduos, e com a necessidade do distanciamento social, evidenciou-se um aumento na quantidade de pessoas buscando atendimento nos serviços de saúde, com queixas relacionadas ao sofrimento mental.

O sofrimento mental é caracterizado por um conjunto de sintomas não psicóticos como a insônia, fadiga, irritabilidade, esquecimento, dificuldade de concentração e queixas somáticas (múltiplas queixas de problemas físicos persistentes que estão associadas a pensamentos, sentimentos e comportamentos excessivos).

Diante desse contexto, torna-se relevante que os profissionais de saúde, principalmente da Atenção Primária à Saúde, busquem alternativas de cuidado voltadas ao alívio de tais sintomas.

Sabe-se que a utilização de ervas e plantas medicinais para tratar sintomas de doenças está muito presente na cultura brasileira, sendo que seu uso além de ser de baixo custo, promove o uso sustentável da biodiversidade e reconhece as práticas populares e tradicionais como forma de cuidado.

Considerando tal prática relevante, uma enfermeira envolveu equipes de Estratégia Saúde da Família, de um município ao norte do Rio Grande do Sul, na realização de uma ação de educação permanente à população voltada à utilização correta de ervas e plantas medicinais, como forma de aliviar os sintomas de sofrimento mental. 
Nesse sentido, foi desenvolvido pela equipe um folder educativo embasado em evidências científicas sobre ervas e plantas medicinais indicadas para tratar os sintomas de sofrimento mental apresentados pelos pacientes no serviço de saúde. Para a elaboração do material, teve-se o cuidado de selecionar ervas e plantas conhecidas e de fácil acesso da população local. Foram incluídas no folder: imagens de ervas e plantas medicinais, sua indicação, dose recomendada, parte a ser utilizada, forma de utilização (infusão, aromaterapia e confecção de travesseiros aromáticos), além de orientações sobre cuidados a cerca da utilização.

Depois da impressão gráfica, os folders foram entregues aos Agentes Comunitários de Saúde para distribuição às famílias e também dispostos na Unidade Básica de Saúde. Espera-se com o desenvolvimento dessa ação educativa ter contribuído para o aumento do conhecimento das pessoas sobre o uso correto e seguro de ervas e plantas medicinais como forma de amenizar os sintomas de sofrimento mental.

\section{OBRAS CONSULTADAS}

BRASIL. Ministério da Saúde. Secretaria de Atenção à Saúde. Departamento de Atenção Básica. Política Nacional de Práticas Integrativas e Complementares no SUS (PNPIC-SUS). Brasília, DF: Ministério da Saúde, 2006. Disponível em: http://bvsms.saude.gov.br/bvs/publicacoes/pnpic.pdf. Acesso em: 13 jun. 2020.

PREFEITURA DE FLORIANÓPOLIS. Secretaria Municipal de Saúde de Florianópolis. PICs e covid-19: Compilado de Práticas Terapêuticas para o autocuidado, fortalecimento da imunidade e bem-viver, durante e após a pandemia. 2. ed. Florianópolis: Secretaria Municipal de Saúde, maio, 2020. Disponível em: https://bit.ly/2IsFMzb. Acesso em: 13 jun. 2020. 